\title{
Unravelling Sideroxydans \\ lithotrophicus ES-1 Fe(II)-oxidizing pathway using transcriptomics and RT-qPCR
}

\author{
NANQING ZHOU, JESSICA KEFFER, SHAWN POLSON \\ AND CLARA S CHAN
}

University of Delaware

Presenting Author: nqzhou@udel.edu

Microaerophilic iron-oxidizing bacteria $(\mathrm{FeOB})$ may catalyze most of the $\mathrm{Fe}$ (II) oxidation in suboxic circumneutral environments and connect iron and carbon cycling. Most known neutrophilic $\mathrm{FeOB}$ are obligate $\mathrm{Fe}(\mathrm{II})$-oxidizers, and thus, the specificity of genes and proteins involved in the Fe(II) oxidation mechanism is not well-resolved. Sideroxydans lithotrophicus ES1 contains genes to oxidize different substrates, including Fe(II) ( $m t o A$, three $c y c 2$ gene copies) and sulfur (sox, $t s d, d s r$ ), making it an ideal model to study the genes that are specifically involved in $\mathrm{Fe}$ (II) oxidation. In our work, we performed transcriptome sequencing on ES-1 grown on either Fe(II) or thiosulfate at different growth phases to investigate the long-term response to substrates. Moreover, we also investigated ES-1's response to a short-term switch from thiosulfate oxidation to $\mathrm{Fe}(\mathrm{II})$ oxidation in a time-series within $90 \mathrm{~min}$. Transcriptomic and RT-qPCR data showed all $c y c 2$ gene copies were expressed orders of magnitude higher than $m t o A$. The three $c y c 2$ genes were all $\mathrm{Fe}(\mathrm{II})$ responsive but differed in their responses in the long and short term experiments. Furthermore, Fe(II) oxidation by ES-1 corresponded to upregulation of reverse electron transport and carbon fixation-related genes, notably alternative complex III and RuBisCo genes. We also identified potential periplasmic electron carriers and a novel cytochrome-containing gene cluster that was $\mathrm{Fe}(\mathrm{II})$ responsive. These results demonstrate $c y c 2$ plays an important role in $\mathrm{FeOB}$ metabolism and can be used to indicate $\mathrm{FeOB}$ activity and the $\mathrm{Fe}(\mathrm{II})$ oxidation potential. However, to demonstrate $\mathrm{Fe}$ (II) oxidation activity may require examination of the full pathway which includes electron transport and $\mathrm{CO}_{2}$ fixation. Our study updated the ES-1 Fe(II) oxidation pathway and provides perspectives on detecting environmental microbial $\mathrm{Fe}(\mathrm{II})$ oxidation activities in environments. 